\title{
Physical Activity for an Aging Population
}

\author{
Abby C. King, $\mathrm{PhD},{ }^{1}$ \\ Diane K. King, $\mathrm{PhD}^{2}$
}

\begin{abstract}
Physical activity has been identified as one of three key health behaviors impacting the major chronic diseases of aging that are increasingly responsible for a substantial proportion of global mortality. Although the scientific evidence indicates that the health and quality of life effects of a physically active lifestyle extend across the life course, midlife and older adults represent the most inactive portion of the population. Among the objectives of this review are to discuss the benefits of an active lifestyle, particularly for older adults; highlight the major issues and challenges currently facing the physical activity and aging field; and explore the types of directions for science, policy, and practice that could positively impact the significant physical inactivity challenge facing a growing number of countries worldwide.
\end{abstract}

Key words: Physical activity, aging, older adults, prevention, ecological

Recommended Citation: King A, King D. Physical Activity for an Aging Population. Public Health Reviews. 2010;32:401-26.

\footnotetext{
${ }^{1}$ Department of Health Research \& Policy, and Stanford Prevention Research Center, Department of Medicine, Stanford University School of Medicine.

${ }^{2}$ Institute for Health Research, Kaiser Permanente, Denver, CO.
}

Corresponding Author Contact Information: Abby C. King at king@stanford.edu; Stanford University School of Medicine, 259 Campus Drive, HRP Redwood Building, T221, Stanford, CA 94305-5405 USA. 
"Lack of activity destroys the good condition of every human being, while movement and methodical physical exercise save it and preserve it."

\section{INTRODUCTION}

It has been argued that successful human aging, in its broadest sense, may reflect an evolutionary adaptation that provides intergenerational support and other societal contributions. ${ }^{1}$ Fulfilling such societal potential, however, requires that older adults maintain levels of daily function and vitality that allow them to participate in the physical and social endeavors occurring around them. ${ }^{2}$ Unfortunately, the current aging process in many industrialized nations is often accompanied by significant declines in physical, cognitive, and/or social function that lead to loss of independence and quality of life, while contributing to substantial economic costs. ${ }^{3}$

In the face of such broad societal challenges accompanying the current global aging trends, such as cost and access to healthcare, obesity and its co-morbidities, housing, and need for community-based services that allow adults to age-in-place, scientists and policy makers have focused increasingly on identifying factors that may have substantial positive impacts on the aging process as well as the quality of life of older adults. One such area is regular physical activity. ${ }^{4-6}$ In fact, the available evolutionary evidence indicates that the human species evolved to be regularly physically active, and up until the middle of the $20^{\text {th }}$ century was generally successful in doing so. ${ }^{7}$ The increasing rapidity with which technological advances have swept industrial societies has led to the unique situation in which we have, in essence, culturally "outrun" our ability to biologically adapt to the very different, and sedentary, environments that we find ourselves in today.

The purpose of this paper is to provide an overview of the contributions, across multiple levels of impact, of an active lifestyle to healthful aging. We discuss the magnitude globally of physical inactivity among older adults, and the major issues and challenges currently facing the physical activity and aging field, particularly with respect to effective intervention development. We also recommend directions for science, policy, and 
practice to address the challenges described. In discussing the field, we apply the standard definition of "physical activity" as "any bodily movement produced by skeletal muscles that results in energy expenditure", in contrast to "exercise" or "sport", which typically has been defined as a subset of physical activity that involves "planned, structured, and repetitive bodily movements done to improve or maintain one or more components of physical fitness". ${ }^{8}$ In addition to the aerobic forms of physical activity (e.g., walking, bicycling, swimming, running) that are recommended across the life course, older adults can benefit from resistance, stretching, and balanceoriented exercises that address the decrements in muscle strength, flexibility, and balance that typically accompany aging. ${ }^{9}$ Notably, research has demonstrated that even the oldest and most frail segments of the older adult population can benefit from regular increases in these types of physical activity when they are tailored to participant needs. ${ }^{10}$

Consistent with the literature, we define "older adult" as ages 50 years and above, given the opportunities for preventing physical and mental decline and the sedentary habits that typically increase during the middle years and beyond. In addition, addressing such factors during middle adulthood enhances the potential to forestall the onset of chronic disease and enhance health and quality of life throughout the many years that often remain to individuals in industrialized nations entering the $6^{\text {th }}$ decade of life. ${ }^{11}$

\section{PHYSICAL ACTIVITY AND AGING - AN ECOLOGICAL PERSPECTIVE}

General ecological models of aging, which describe the interrelationships between individual competencies and the surrounding environmental context, have been discussed over a number of decades, ${ }^{12}$ and have grown in both comprehensiveness and detail. ${ }^{13}$ An ecological framework specific to physical activity is shown in Figure 1 and includes examples of personal (i.e., biologic, behavioral, demographic), social/cultural, and environmental/ policy levels of impact. The framework also includes the influence of time (e.g., cohort and period effects; daily, weekly, or more extended time effects that can become targets for assessment as well as intervention), and developmental or life course effects (e.g., menopause, retirement, bereavement) across all levels of impact. ${ }^{13}$ Note that the ecological 
framework can be used to organize physical activity-relevant outcomes (e.g., health status and function, neighborhood- or community-level social capital), determinants (e.g., cultural beliefs related to physical activity, neighborhood walkability), as well as interventions (e.g., enhanced social support for regular physical activity, economic incentives aimed at encouraging physically active lifestyles).

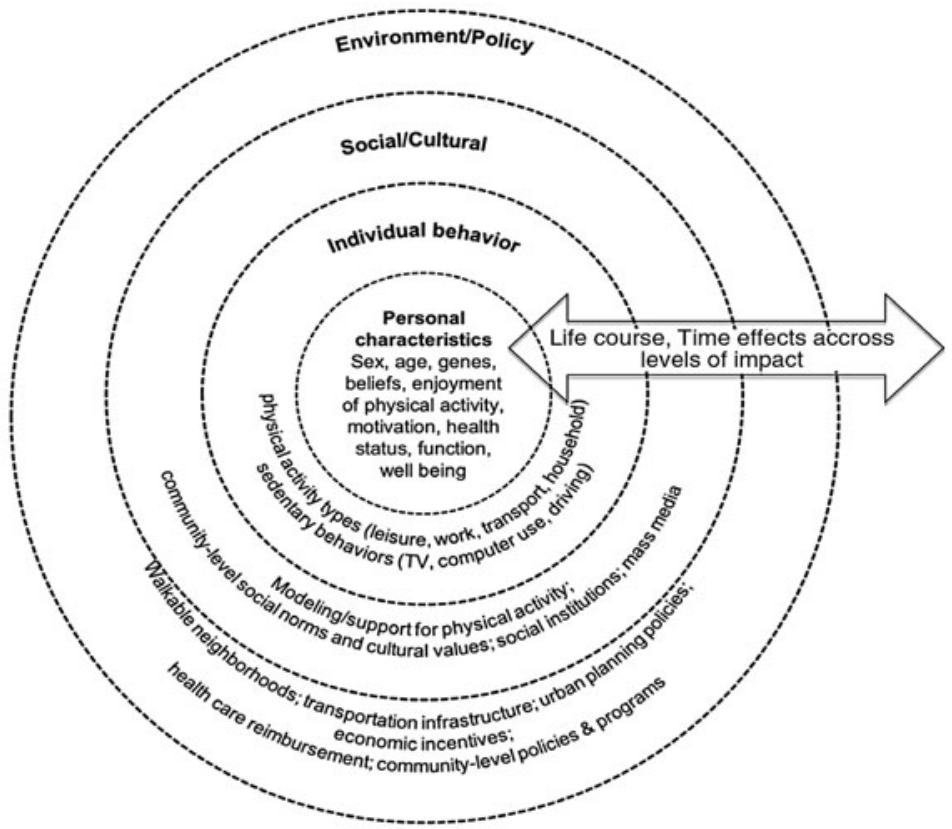

Fig. 1. A social ecological framework for population physical activity Promotion.

Source: Adapted from: Institute of Medicine. Health and behavior: The interplay of biology, behavioral, and social influences. Washington, (DC): National Academies Press; 2001; and King AC, Sallis JF. Why and how to improve physical activity promotion: lessons from behavioral science and related fields. Prev Med 2009;49:286-8.

\section{THE BENEFITS OF LIFELONG PHYSICAL ACTIVITY}

As the quotation at the beginning of this article attests, much has been written, beginning in ancient times, about the potential salutary effects of a physically active lifestyle on health and aging. Such early observations have been borne out through the accumulation, over the past 70 years, of a 
prodigious scientific literature that has underscored the importance of regular physical activity to health, function, and quality of life across the life course. ${ }^{5,9}$ While regular physical activity has been shown to positively impact health and function across all age groups, beginning prenatally, ${ }^{14} \mathrm{a}$ regular physical activity regimen may have particularly beneficial effects in the later years, ${ }^{5}$ and may in fact slow the aging process. ${ }^{11}$ The anticipated increase in chronic conditions associated with aging, as well as their accompanying strain on the healthcare system, presents a strong argument for promoting habitual physical activity as a primary prevention strategy. In addition to the strong relationship between physical inactivity and allcause mortality, ${ }^{15,16}$ chronic diseases and health conditions that have been strongly linked with an inactive lifestyle are cardiovascular disease, stroke, type 2 diabetes, some forms of cancer (i.e., colon, breast), depression, dementia, decline in physical function, and weight gain. ${ }^{9}$ Additional health areas of relevance for older adults for which an association with regular physical activity has been found include improved sleep quality, lower risk of hip fracture and increased bone density, reduced abdominal obesity, lower risk of lung and endometrial cancers, weight maintenance following weight loss, and positive well-being and quality of life. ${ }^{9}$ Regular physical activity may also help to mitigate some of the negative health outcomes that typically accompany life course periods such as menopause. ${ }^{17}$ While definitive evidence is currently lacking concerning the effects of regular physical activity on aging-related disability (defined by Nagi as limitations in performance of socially defined roles and tasks within a sociocultural and physical environment), ${ }^{18}$ at least one large multi-center randomized controlled trial, Lifestyle Interventions and Independence for Elders (LIFE), is currently underway in the United States to specifically answer this question. ${ }^{10}$

Physical inactivity, measured using either self-report or objective assessment tools, has been identified as one of three key health behaviors (in addition to tobacco use and dietary patterns) that together are responsible for approximately 50 percent of global mortality. ${ }^{19}$ Of note, the epidemiological evidence indicates that it is current or recent levels of physical activity, as opposed to previous physical activity patterns, that are in general more strongly predictive of major health outcomes. ${ }^{20}$ The epidemiological evidence indicates further that even reasonably low levels of less intensive activities such as walking can be health-protective in older adults. ${ }^{16}$ The principal challenge facing the field concerns finding ways to increase population levels of physical activity by these generally feasible and relatively modest amounts in order to obtain the plethora of health and quality of life benefits indicated by the current evidence base. 


\section{PHYSICAL INACTIVITY - THE MAGNITUDE OF THE PROBLEM}

Over the past several decades, a growing number of nations have tracked physical activity levels among their populations and by population subgroups based on age and other characteristics. The epidemiological picture that has emerged from population surveillance data reflects high levels of physical inactivity (e.g., no leisure-time physical activity, ranging from 20-30 percent of the population or more) that generally increase with age. ${ }^{21,22}$ High physical inactivity rates are reported in many industrialized countries, as well as in a growing number of developing nations. ${ }^{23}$ Physical activity levels among older adults, as well as their younger counterparts, typically fall well below the 150 minutes or more of weekly moderateintensity physical activity (i.e., akin to brisk walking) currently recommended by a growing number of nations to achieve optimal health benefits. ${ }^{9,24}$ The fact that more moderate forms of physical activity that are particularly attractive to midlife and older adults (e.g., walking) have been demonstrated to positively impact health, ${ }^{25}$ even when undertaken in reasonably short episodes (e.g., 10 minutes), provides a wealth of opportunities for population physical activity promotion.

\section{APPLYING AN ECOLOGICAL FRAMEWORK IN PROMOTING AN ACTIVE LIFESTYLE AMONG OLDER ADULTS: PHYSICAL ACTIVITY CORRELATES}

In light of the magnitude of the physical inactivity challenge across the older adult population, interdisciplinary multi-level approaches, as reflected in a social ecological health behavior model, are required to advance the field (Figure 1). ${ }^{13}$ At the personal level of influence, older adults' choices to be regularly physically active are influenced, similar to other age groups, by a host of attitudinal, cognitive, and behavioral variables, including erroneous beliefs related to physical activity (e.g., exercise and exertion "waste" energy; "no pain, no gain", etc.); self-efficacy (i.e., an individual's confidence in being able to engage in physical activity across a specified time period); expectations of benefits; physical activity enjoyment; and competence in using self-regulatory skills that can enhance and maintain health behavior change (e.g., realistic goal-setting, regular tracking of physical activity), including use of portable tools, such as pedometers and other devices, to obtain behavioral feedback. ${ }^{26,27}$ At least some of these factors may underlie the well-established demographic and health characteristics that are associated with lower physical activity levels across 
a range of populations, including greater age, female sex, lower levels of education, lower household income levels, lower rated health, unemployment status, increased body weight, cigarette smoking, depressed affect, living in certain regions or locales (e.g., rural or disadvantaged areas of some countries), and belonging to certain racial or ethnic minority groups. ${ }^{28,29}$

In addition to the above list of personal-level physical activity correlates, a growing number of factors of particular relevance to older adults have been identified. These include impairments related to physical or cognitive function, and the individual's belief that physical activity is important to his or her own health. ${ }^{30}$ Of relevance to a life course perspective, there also is some evidence that physical activity experiences occurring in childhood or adolescence can set the stage for physical activity participation in adulthood, potentially extending through old age. ${ }^{31}$

The majority of the scientific literature in the physical activity field to date has been aimed at personal level influences. ${ }^{32}$ As part of this focus, there has been an overreliance on a medical model perspective that conceptualizes the issues in a clinical as opposed to a public health or community-based context. Often accompanying such a perspective has been an emphasis on personal responsibility that typically fails to recognize the social and environmental circumstances within which physical activity and other health behaviors occur. Greater emphasis on person-environment interactions remains a current challenge for the field. ${ }^{33}$

At the social/cultural level of influence are immediate interpersonal levels of support from family, friends, neighbors, and other community members. Physical activity advice from physicians and other healthcare providers also may be potentially beneficial for some groups of adults and older populations..$^{30}$ In addition to such immediate forms of social influence, cultural and religious norms, values, taboos, and expectations can influence individual behavior, and even the institution of marriage may not necessarily support a more physically active lifestyle. ${ }^{34}$ In addition, older adults who are gay, lesbian, bisexual, or transgender are disproportionately more likely to live alone than heterosexual seniors and are at a much higher risk for poverty, homelessness, and social isolation - factors linked with detrimental health behavior patterns. ${ }^{35}$ All of these areas of research underscore how understanding the social and cultural contexts, along with potential gaps in availability of relevant support for physical activity, are critical.

Currently, many physical activity programs around the world aimed at older adults utilize a group-based structure that can provide older adults with a level of ongoing support for physical activity change that many midlife and older adults (albeit not all) may find helpful, particularly in the short-term..$^{36,37}$ Group interventions that include cognitive-behavioral strategies to optimize 
longer-term adherence may be particularly helpful. ${ }^{38}$ Relatively little attention, however, has been aimed at understanding and systematically harnessing the natural social networks of older adults (e.g., family, friends, neighbors, healthcare providers, pharmacists and other community service personnel, community and faith-based organizations) that may provide a more powerful and sustainable influence on physical activity levels. Dog ownership may also serve as another social stimulus for increased physical activity. ${ }^{39}$ In addition, continued attention is needed to reach those midlife and older adults who eschew structured settings or group contexts..$^{40,41}$ In at least some countries, this segment of the aging adult population may be reasonably large, and may include adults of more advanced age and diminished physical health ${ }^{42}-$ subgroups that may particularly benefit from even modest increases in physical activity. ${ }^{9}$ In one of the few experimental investigations that compared systematically the long-term (2-year) effects of a structured group versus home-based program in sedentary adults ages 50-65 years, persons randomized to a telephone-supervised home-based program showed significantly greater 1 - and 2-year physical activity participation rates relative to persons randomized to the structured group program..$^{43}$ Other investigators have noted the relative strength of structured home versus group-based physical activity programs, particularly over the long-term, in producing higher adherence rates in varied populations of older adults. ${ }^{37}$

In addition to such interpersonal factors, socioeconomic and cultural characteristics of the broader community, including institutional factors (e.g., education, housing, healthcare, employment), can play a role in impacting physical activity levels. ${ }^{44}$ For example, lack of tangible resources emanating from poor economic conditions and circumstances (e.g., lack of transport to physical activity-conducive settings; crime) can pose barriers to a physically active lifestyle, particularly among the older segment of the population that, in a number of countries, faces challenges related to retirement as well as economic insecurity. ${ }^{3}$ Socioeconomic disparities are also linked with the observed gradients in frailty and disability in old age, associated with physical inactivity, that have been reported in North America, Europe, and elsewhere.

Opportunities among older adults for continued employment and/or volunteer activities can influence vitality, quality of life, and indirectly, health behaviors such as physical activity. For example, an experimental evaluation of an older volunteers primary school program in a disadvantaged US community, called Experience Corps, which was designed intentionally to promote physical as well as cognitive and social activity among older volunteers while improving children's academic success, indicated that the older volunteers experienced significant increases in physical activity, strength, perceived social resources, and cognitive activity across a 4 - to 8 -month period relative to controls. ${ }^{45}$ 
In addition to the above domains, cultural expectations, norms, and proscriptions related to physical activity and aging can encourage or discourage regular physical activity participation. In some societies, for example, older women may be exposed to societal messages discouraging physical activity participation. ${ }^{46,47}$ Similar types of cultural or religious beliefs, norms, and expectations may play a role in the lower levels of physical activity reported in some ethnic minority and low-income groups. ${ }^{47}$ Such factors may take the form of lack of appropriate role models for a physically active lifestyle, language barriers, family and care-giving duties that leave little time for health-enhancing physical activity, and a lack of culturally relevant physical activity programs (e.g., traditional dance).$^{47,48}$

Finally, mass media can convey messages promoting or dissuading physical activity that, in combination with other contextual factors, may impact awareness and/or motivation related to physical activity. ${ }^{49}$ The plethora of media channels to which older adults can be regularly exposed currently, including television, radio, newspapers and other forms of print, and Internet, increase the complexities of the current informational and social environments surrounding them, but also provide potentially rich avenues for broad-based education and health behavior change. ${ }^{49}$ Identifying the most efficient ways of integrating effective physical activity messages across media outlets represents a promising means for reaching the older population that awaits further investigation. ${ }^{49}$

At the environmental/policy level of influence are physical environment factors such as climate and seasonal effects ${ }^{50}$; objective and subjective features of the built environment (e.g., walkability characteristics such as proximity of desirable destinations, pedestrian amenities including sidewalks or footpaths, adequate lighting, and intersection crossing features; aesthetics such as foliage, pleasant scenery $)^{51}$; housing, transportation, and zoning policies ${ }^{52}$; and impacts of legislation and economic policies related to taxation, incentives, reimbursement systems, and related areas (e.g., fiscal support of parks and other recreational features) with direct or indirect connections to physical activity. ${ }^{53}$ Notable examples of such national and regional policies include the national transportation policies legislated in the Netherlands to optimize the use of existing infrastructure to improve accessibility by public transportation and bicycle; and London's "congestion charge", which is aimed at reducing traffic congestion and encouraging people to choose other forms of transport." Use of public transportation has been linked with greater amounts of walking and cycling. ${ }^{52}$ Type of housing also has implications for levels of utilitarian activity performed, such as yard work. ${ }^{2}$

\footnotetext{
* Available from URL: www.tfl.gov.uk/roadusers/congestioncharging/ (Accessed 5 April 2011).
} 
While the current evidence base in this area is relatively small and consists primarily of cross-sectional studies, it supports the promise of such strategies on population-wide physical activity levels, including among older adults. Although currently there is little experimental evidence clarifying the directionality of the built environment-physical activity relationship (i.e., whether more active adults may choose to live in more "walkable" neighborhoods), the available observational evidence suggests that selfselection alone cannot fully explain the physical activity-built environment relationship. ${ }^{54}$ Furthermore, there is growing evidence that many older adults are aging in neighborhoods that do not support their needs. ${ }^{52}$ In fact, older adults who are lower income or from ethnic minority groups have an increased probability of staying in, or migrating to, less desirable living situations in later life, ${ }^{55}$ adding further evidence that self-selection cannot adequately explain the health behavior-environment relationships observed.

\section{MAJOR CHALLENGES CURRENTLY FACING THE PHYSICAL ACTIVITY PROMOTION AND AGING FIELD}

If the increasingly inactive lifestyles that have developed in many populations in the latter portion of the $20^{\text {th }}$ century are to be halted or reversed in the $21^{\text {st }}$ century, a number of challenges will need to be addressed. Several of the more pressing challenges in the field are highlighted below.

\section{Lack of a systems approach to thinking about physical activity solutions}

Scientists and scholars in the field have done a generally admirable job of delineating the many problems attendant with an inactive lifestyle throughout the life course. ${ }^{9,33}$ Much less systematic attention, however, has been paid to developing comprehensive, sustainable solutions to the physical inactivity challenges facing an increasing number of countries around the world. To date, many of the interventions that have been tested have engaged perspectives from a limited number of disciplines, focused largely on a single level of impact (primarily the personal level), targeted relatively short time frames (e.g., 4 to 12 months), paid little attention to external validity (i.e., generalizability, translatability), and targeted and measured only one form of physical activity (e.g., leisure-based physical activity). Applying such a narrow perspective, in addition to leading to inadequate or incomplete solutions, can have unintended consequences for one population subgroup when policies or programs are put in place for a different population subgroup. ${ }^{56}$ For example, the increasing recognition by 
urban planners, transportation experts, and public health experts of the importance of "walkable" urban environments for non-motorized transport (walking or bicycling to work or to accomplish errands) among working age segments of the population has created a sense that optimal levels of physical activity may only be attainable in such environments. In this literature, the urban planning-based definition of "walkable" (i.e., having high residential density, mixed use, and adequate street connectivity, among other characteristics) has been applied. ${ }^{52}$ Yet, in applying the results from a literature that has largely ignored non-working age residents (e.g., children, older adults), and focused largely on commuting behaviors, a potentially constrained view of both the problem and potential solutions may emerge. Indeed, some recent investigations have reported that some groups of children and teenagers are more active in cul-de-sac-oriented street designs (i.e., those with less street connectivity) ${ }^{57}$ Similarly, some groups of midlife and older women attempting to increase levels of health-enhancing physical activity have succeeded in becoming more regularly active when living in neighborhoods with less residential density and mixed use (i.e., more suburban style neighborhoods) relative to older women living in more mixed-use neighborhoods. ${ }^{58}$ Explanations for both of these ostensibly anomalous findings may center on the form of physical activity being performed (in this case, recreational or leisure activity), and the reduced traffic levels typically accompanying neighborhoods with less residential density and mixed use - a positive factor for population subgroups that may be more vulnerable to the deleterious effects of traffic., ${ }^{2,58}$

\section{Lack of specificity in the current physical activity promotion evidence base}

As alluded to above, the physical activity promotion literature to date reflects a reasonably simplistic and uni-dimensional conceptualization of the physical inactivity problem as well as potential solutions. During the latter portion of the $20^{\text {th }}$ century, a primary focus of the field centered on answering the questions, "How much physical activity is enough to obtain health benefits?" and "Which interventions work to increase regular physical activity?" Arguably, in the current century, the pressing, and far more complex, question to be answered relates to identifying which interventions should be aimed at which subgroups of the population to impact which types or forms of physical activity (e.g., for leisure, for transport, etc.) in order to achieve which health, functioning, and/or quality of life outcomes. While higher-level approaches (e.g., national policies) may indeed positively impact broad segments of the population, including 
many older adults, it remains the case that older adults, by virtue of their heterogeneity both within this age group as well as in comparison to younger age groups, will likely benefit from intervention approaches that are targeted to their specific needs, preferences, and circumstances. This situation calls for the development of an array of complementary strategies involving multiple sectors, disciplines, targets, and levels of impact that share common messages and can be delivered in a cost-conscious fashion.

\section{Addressing health disparities as part of the physical activity and aging agenda}

In many nations, health disparities remain a major and growing concern that can have particularly untoward effects on older adults, given their often increasing physical and cognitive vulnerabilities and reduced economic circumstances relative to working-age adults. ${ }^{55}$ In the US, the recent economic downturn has led to reports by 25 percent of adults ages 45 to 64 years that they are raiding their retirement accounts, postponing paying bills, skipping medications and doctors appointments, and postponing retirement indefinitely. ${ }^{59}$ According to a survey conducted by the American Association of Retired Persons (AARP) ${ }^{60}$ older Americans are filing for bankruptcy in record numbers, and community resources, such as transportation, meal services, and other home assistance programs, are at risk. Sixty-nine percent fear increased crime in their neighborhoods as housing foreclosures climb. According to the Survey of Health, Ageing, and Retirement in Europe (SHARE), perceived economic inadequacy, whether due to personal or national circumstances, is associated with older adults avoiding healthcare services. ${ }^{61}$

Socioeconomically disadvantaged populations across the life span typically have been found to have among the lowest levels of health enhancing physical activity, and relatively few rigorously developed interventions to date have been specifically targeted to such populations. Multi-level approaches, particularly involving targeting of environmental infrastructure and relevant health policies conducive to physical activity, may be especially indicated, given that infrastructure and resources are often especially lacking in disadvantaged communities. ${ }^{62}$ Increasing and maintaining an active lifestyle may help to buffer older individuals from chronic diseases and conditions of aging that can pose particular threats to those lacking economic or health-related resources, while potentially providing a means of facilitating neighborhood or community-level social networks and opportunities for engagement. 


\section{Sedentary behavior as a separate target for study and intervention development}

In recent years, there has been growing acknowledgement of the importance of sedentary behaviors, such as prolonged sitting and television viewing, as risk factors for important health outcomes independent of physical activity levels. For example, prolonged television viewing time (defined typically as two or more hours per day) has been associated with overweight and obesity, type 2 diabetes and abnormal glucose metabolism, and the metabolic syndrome. ${ }^{63,64}$ Among the factors that have been linked with increased television viewing time are older age, poorer health, lower levels of education and income, unemployment, overweight or obesity, financial costs to physical activity, family and work commitments, feeling tired, and poor weather. ${ }^{65}$ While systematically increasing regular physical activity among adults ages 50 years and older has not been associated with natural decreases in sedentary activities, ${ }^{66}$ at least one study of overweight or obese younger adults reported that short-term (3-week) systematic reductions in television viewing time was associated with increases in energy expenditure. ${ }^{67}$ The long-term health, social, and quality of life impacts of interventions aimed at reducing television viewing time and other sedentary activities among older adults remains to be explored.

\section{RECOMMENDED DIRECTIONS FOR ACTION AIMED AT PHYSICAL ACTIVITY PROMOTION}

The large and growing magnitude of the physical inactivity problem worldwide, its demonstrated impacts on a range of chronic diseases and conditions associated with aging, and the observation that increases in regular physical activity, to even a modest degree, can positively impact health, daily function, and quality of life in advanced age provide a compelling argument for transforming the ways in which scientists, policy makers, and practitioners have typically approached this important public health arena. Recommendations for science, policy, and practice are described below.

\section{Science}

Similar to other health areas (e.g., obesity), it has become increasingly clear that transformative scientific advances in the physical activity promotion field will likely require proactive applications of an interdisciplinary and multi-level systems approach to intervention development and evaluation. ${ }^{32,68}$ Although the complexities of delineating and evaluating a comprehensive 
systems approach to scientific enquiry in the field may appear overwhelming and cost-prohibitive, initial steps towards this multi-level goal can be taken. For example, the potential impact of frequently studied personal-level physical activity interventions can be increased through expanding the "reach" and translation of effective interventions to broader segments of the older adult population. Examples of this type of "bottom up" approach to broadening interventions in the field include the use of trained community volunteers and service sectors in intervention delivery and evaluation, ${ }^{69,70}$ as well as development and evaluation of state-of-the-art communication technologies to broaden intervention delivery in a potentially cost-sensitive manner. ${ }^{49,71,72}$ Notably, older adults represent one of the fastest growing user groups of computers as well as Internet and social networking services. ${ }^{73}$ Information technologies thus represent an increasingly pervasive and promising method for delivering health services and support, ${ }^{74}$ including preventive health services, to them. ${ }^{75}$ The globalization of population-wide mobile phone use in developing as well as industrialized nations promises to extend the potential reach of such communication platforms even further. ${ }^{76}$

An additional facet of the "bottom up" research approach involves the explicit evaluation of the person by environment interactions in order to gain a more thorough understanding of the potential moderating effects of built and social environments on physical activity change. ${ }^{58}$ This type of understanding can, in turn, drive subsequent intervention development aimed at environmental levels of impact, particularly as they pertain to specific subgroups of older adults.

Complementing such "bottom up" research approaches are "top down" research strategies that take advantage of the growing number of observational studies worldwide focused on the built environment and physical activity. ${ }^{77}$ By including in such observational research designs explicit evaluations of built environment relationships for specific subgroups, such as older adults, a better understanding of subgroup by environment effects can ensue.

Implicit in the above perspectives is the growing awareness of the critical need for community-based participatory research (CBPR) methods for the physical activity promotion field as a whole, including research aimed at older populations. ${ }^{7879} \mathrm{CBPR}$ methods recognize the key role that community members and organizations can play in advancing the evidence base in a manner that optimizes the relevance and appropriateness of interventions and results for those who represent the ultimate beneficiaries of the research. ${ }^{78,79}$ Such perspectives tend to be solution-oriented, and can help in delineating a broad web of problem and solution linkages of 
particular relevance to systems-oriented research ${ }^{80}$ An example of a CBPRbased problem and solution tool for identifying key multi-level and multisectoral determinants in the physical activity and aging area, adapted from the population intervention work of Snowdon and colleagues ${ }^{80}$ and others, is shown in Figure 2. The main question used to aid the development of the problem portion of the tree is "why" (i.e., why does the situation occur?). Beginning with the starting problem (identified in Figure 2 as "low levels of physical activity"), a multidisciplinary group (optimally including, in this case, individuals representing such fields as public health, relevant science fields, community senior advocacy, local business, and planning, transportation, and policy experts) works together to identify the factors contributing to the starting problem and its branching problems, and so on. This process builds up levels or layers of underlying factors or determinants (represented as roots and lower-level branches). The process can continue until the analysis reaches a point where solutions become apparent, or when a certain number of levels, (e.g., three), have been detailed. Once the "roots" and "branches" have been completed and potential solutions identified, a final check is done to ensure that the tree "works", i.e., that the statements are logical and reasonable, and that identified solutions lead back to the starting problem and branching problems being discussed.

In the problem-solution tree example shown in Figure 2 (which is illustrative as opposed to exhaustive), the solid-line boxes represent the types of problems, identified in the literature as well as by community members, underlying low levels of physical activity among older adults. The starting problem (i.e., low levels of physical activity) splits into two different sub-problems - low levels of active transport and low levels of leisureoriented physical activity - that likely require some unique solutions in addition to solutions that may overlap. The dashed-line boxes represent examples of relevant solutions. Note that both the problems and the potential solutions occur across levels of impact. For example, personal level problems include functional impairments and fear of falling; sociocultural level problems include norms that do not support physical activity for seniors; and environmental level problems include lack of attractive destinations for seniors and street designs and amenities that do not support walking. Some of the potential solutions could benefit both transport-based and leisure-time physical activities (e.g., enforcing neighborhood speed limits; sidewalk maintenance), while others (e.g., forming neighborhood walking groups, re-zoning to attract destinations attractive to older adults) would likely impact primarily one type of physical activity versus the other. 


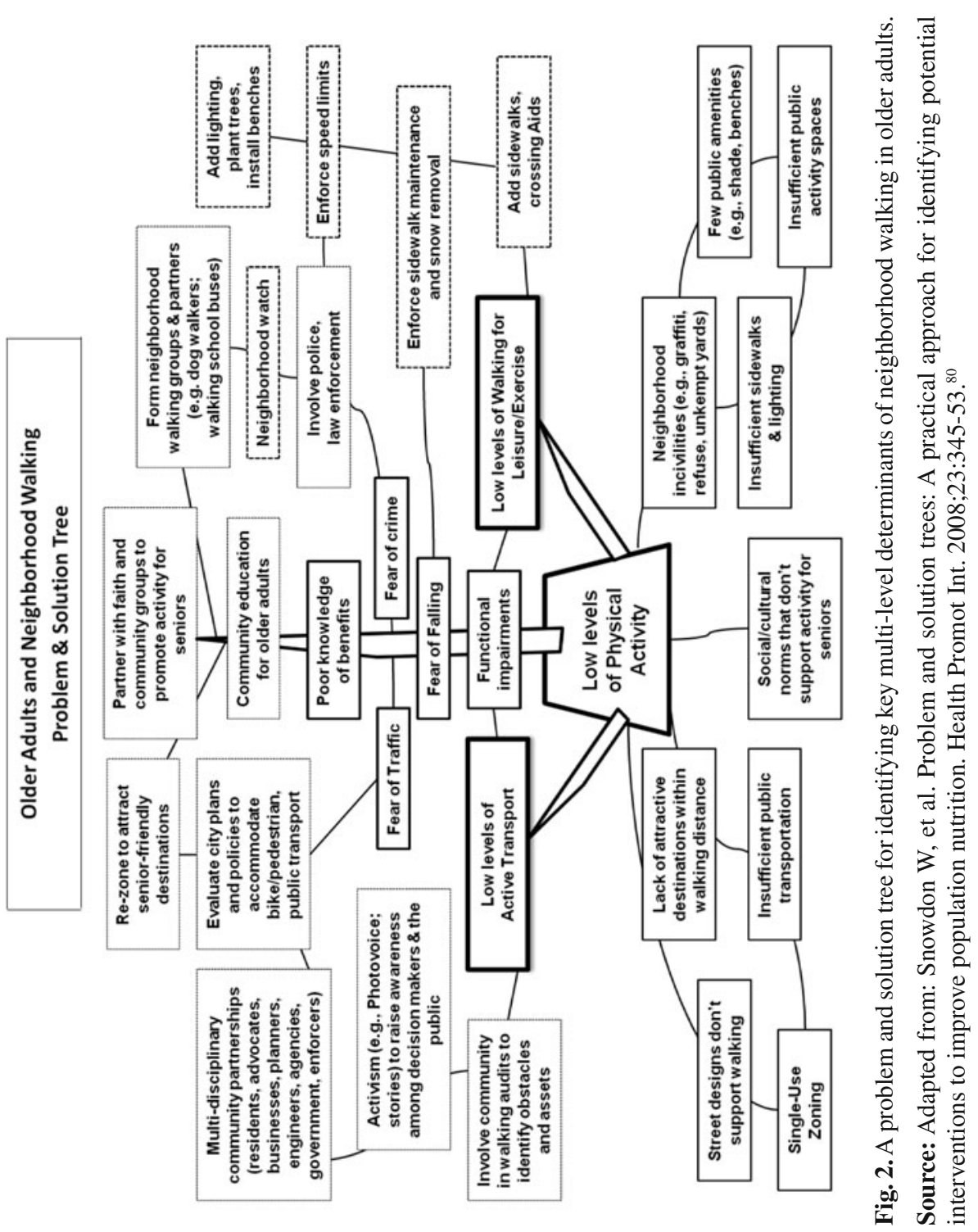


The problems that impede older adults' physical activity levels, while involving some areas that are reasonably universal, also typically will involve areas that are unique to a community. Therefore, the development of problem-solution trees specific to a particular locale will likely be most relevant and productive. It is also important to note the positive benefits to younger community residents as well as to other areas and sectors (e.g., air quality, crime control) that could be realized for many of the solutions that were identified in Figure 2. As noted earlier, it is important additionally to identify any untoward problems for other community residents and/or sectors attendant with the solutions being developed. ${ }^{56}$

Successful CBPR activities and community-organizing approaches to disseminating sustainable evidence-based interventions require a mutual investment in team building and shared resources, ideas, and expertise, as well as flexibility in applying a range of research methods and designs that support increased external validity and intervention sustainability. ${ }^{79}$ Examples of such pragmatic designs include the identification, in collaboration with personnel from the community practice and policy sectors, of "natural experiments" or uncontrolled pretest-posttest designs to study interventions of relevance to the physical activity and aging field. Additional examples include evaluations of the process of developing community infrastructure and support (e.g., community coalitions) that can facilitate multi-level community changes aimed at physical activity promotion.

Of relevance to CBPR and systems oriented research perspectives, scientists in the physical activity promotion field would benefit from obtaining a more thorough working knowledge of complementary disciplines and fields not traditionally included in research in this area (e.g., economics, genetics, community design, policy research) that could broaden both the insights and impacts of research in the field. Firmer linkages with fields such as the health economics field, for example, could improve the evidence base related to intervention cost-effectiveness and comparative effectiveness - areas of increasing importance in the current economically constrained climate.

Finally, aging involves a number of different life transitions that often present a range of challenges for many adults. The impacts of such agingrelated life transitions, including menopause, retirement, bereavement, and family caregiving/caring, on physical activity levels, preferences, and barriers are less well understood than other physical activity promotion areas and deserve additional attention. A clearer understanding of the multi-level impacts of these common life transitions on physical activity, in all of its forms (e.g., for leisure, transport, household maintenance, etc.) can potentially inform more powerful interventions. 


\section{Policy}

Policy level interventions represent arguably the broadest and most powerful means for enacting physical activity changes at the population level. Thus far, however, policy level approaches in this field are in their infancy. Policy approaches will necessarily differ depending upon a number of factors, including national, regional, and local governmental structures; cultural mores and traditions; and resource constraints. Among the types of policy strategies that may be of relevance to the physical activity and aging field are methods for including or expanding physical activity promotion programs as part of governmental funding schemes and practices aimed at older adults; local, regional, and national taxation and pricing policies that could impact choice and behavioral decision-making related to physical activity or other behaviors with known relationships to physical activity participation (e.g., driving); governmental funding for improving the physical activity infrastructure, particularly in lower-income locales; and policy development and collaborations with other sectors and areas where potential synergies with physical activity promotion may occur, such as transportation, housing, energy conservation and sustainability, nutrition, and environmental access for those with disabilities.

Policy efforts aimed at physical activity promotion potentially can be aided, where applicable, by the development of broader surveillance systems for physical activity, broken out by age, that provide benchmark information at local, regional, and national levels. Through such systems, policy changes that may have an impact on physical activity levels can more readily be evaluated. Similarly, developing methods for tracking proposed and enacted governmental legislation aimed at healthful lifestyles, including physical activity, as well as community design and access initiatives, may be useful in advancing the field. As part of such activities, identifying potential natural experiments related to looming policy changes and initiatives can provide a cost-efficient and timely means for collecting much needed information in the field. To optimize such activities, it will likely be important for those in the policy sector to partner with researchers with expertise in evaluation methods. Identifying ways to proactively facilitate such productive partnerships between the policy and science sectors represents a critical need in the field.

Finally, a growing number of countries have or are in the process of developing a national plan to advance the physical activity promotion agenda. ${ }^{81,82}$ While in most cases it is too early to know how effective such plans will be, the fact that a growing number are action-based and involve multiple sectors and disciplines is encouraging. A key question concerns 
how explicitly such plans will take into account the diverse needs and preferences of the older population. Plans that seek to capitalize on natural inter-generational activities and synergies, thereby facilitating regular physical activity across age groups, may be especially indicated.

\section{Practice}

There are a number of practice-based approaches that could potentially impact the physical activity and aging field. One such approach involves the development of viable and sustainable community referral systems for physical activity instruction and support that are available to the healthcare sector as well as other community agencies and organizations. The small body of research evaluating the utility of such community referral systems is currently mixed ${ }^{83}$ Incorporating a greater level of culturally competent physical activity promotion information and community resource identification in health professional training curricula (e.g., for physicians, pharmacists, dietitians, nurses, psychologists, physical and occupational therapists, social workers) also is indicated. As part of such curricula, the needs and preferences of older populations, including those who are most at risk for health disparities, should be made clear, as should the benefits of increases in regular physical activity as a complement or empirically supported alternative to pharmacological treatments aimed at chronic disease prevention and management (e.g., osteopenia/osteoporosis, type 2 diabetes). ${ }^{9}$ Application of the current evidence base in developing, in a more thorough fashion, clinical preventive services guidelines that explicitly incorporate, wherever appropriate, regular physical activity recommendations remains to be realized. ${ }^{84}$ In a related area, training healthcare providers across disciplines in providing simple, time-efficient advice related to the specific benefits of a physically active lifestyle tailored to the patient's health needs can reinforce similar messages emanating from other sectors. Surveys indicate that relatively few healthcare providers deliver such messages on a regular basis..$^{85}$

Where relevant, it may be useful to build greater physical activity expertise and capacity among public health practice groups, as well as develop methods for enhancing cross-disciplinary competencies and partnerships with planning, land use, and transportation experts. Harnessing the energy, resources, expertise, and advocacy skills of non-profit and nongovernmental organizations is also indicated. For instance, the YMCA an organization with a long-standing commitment to physical activity throughout the communities it serves - has a presence in many communities throughout North America, Europe, Australasia, and Asia. In addition to the 
public and non-profit sectors, the private sector, by virtue of its policies and practices related to its retiree population, may provide a useful target for physical activity programs and initiatives that deserves further exploration.

\section{CONCLUSIONS}

As the global population ages, the multi-level determinants of health, function, and quality of life, combined with the prevalence of increasingly inactive lifestyles worldwide, underscore the need for bold, collective actions across sectors and disciplines if the current population trajectories in this area are to be substantively impacted. In particular, identification of ways of broadening traditional "aging in place" paradigms beyond the home setting to the surrounding built and social environments are indicated. Such a paradigm shift involves moving beyond medical model perspectives in embracing multi-level systems approaches that, while more complex, hold promise for impacting population-wide physical activity levels across the life course.

Finally, a systems approach to physical activity promotion that explicitly includes the aging adult segment of the population may benefit particularly from recognizing and targeting those societal values and cultural perspectives that extend beyond health. The potential utility of this type of "stealth" approach to physical activity programming and intervention that targets those values and beliefs that are held dear by many in the older adult community deserves greater attention. Such values and beliefs include positively contributing to society and to subsequent generations, maintaining independence, providing a legacy of betterment to one's culture and community, upholding cultural values and traditions, honoring those who went before, and protecting the lives and livelihoods of ones coming after. Through capturing such societal values, more potent and sustainable solutions to this major public health challenge will be enacted. Such solutions may, in turn, produce important benefits to the individual while paving the way for greater civic engagement and community contribution that can fulfill the promise of a long life.

\section{Acronyms list:}

$\mathrm{CBPR}=$ Community-based participatory research

\section{Key points :}

- Regular physical activity, of even a more moderate intensity, is an established independent risk factor for a range of chronic diseases and conditions associated with aging.

- In a growing number of countries, midlife and older adults represent the most inactive segment of the population. 
- To address the global physical inactivity crisis among older populations and other community members, a systems approach that applies a multi-level ecological framework and an array of actions aimed at science, policy, and practice is needed.

Acknowledgements: Dr. Abby King was supported by U.S. Public Health Service grants R01 HL077141, R01 HL089694, R21 CA127511, RC1 HL099340, and U01 AG022376.

Conflicts of Interest: None declared.

\section{REFERENCES}

1. Lee RD. Rethinking the evolutionary theory of aging: transfers, not births, shape senescence in social species. Proc Natl Acad Sci U S A. 2003;100:9637-42.

2. King DK. Neighborhood and individual factors in activity in older adults: Results from the Neighborhood and Senior Health Study. J Aging Phys Act. 2008;16:144-70.

3. Gonyea JG. The economic well-being of older Americans and the persistent divide. Public Health \& Aging Report. 2005;15:1-11.

4. World Health Organization. The Heidelberg Guidelines for promoting physical activity among older persons. J Aging and Phys Act. 1997;5:1-8.

5. American College of Sports Medicine. ACSM Position Stand on Exercise and Physical Activity for Older Adults. Med Sci Sports Exerc. 1998;30:992-1008.

6. Sheppard L, Senior J, Park CH, Mockenhaupt R, Chodzko-Zajko W, Bazzarre T. The National Blueprint Consensus Conference Summary Report: Strategic priorities for increasing physical activity among adults aged $>50$. Am J Prev Med. 2003;25:209-13.

7. Eaton SB, Eaton SB, III. An evolutionary perspective on human physical activity: implications for health. Comp Biochem Physiol Part A. 2003;136:153-9.

8. Caspersen CJ, Powell KE, Christenson GM. Physical activity, exercise, and physical fitness: Definitions and distinctions for health-related research. Public Health Rep. 1985;100:126-30.

9. Physical Activity Guidelines Advisory Committee. Report of the Physical Activity Guidelines Advisory Committee, 2008. Washington (DC): U.S. Department of Health and Human Services; 2008.

10. Pahor M, Blair SN, Espeland M, Fielding R, Gill TM, Guralnik JM, Hadley EC, King AC, Kritchevsky SB, Maraldi C, Miller ME, Newman AB, Rejeski WJ, Romashkan S, Studenski S. Effects of a physical activity intervention on measures of physical performance: Results of the Lifestyle Interventions and Independence for Elders Pilot (LIFE-P) Study. J Gerontol A Biol Sci Med Sci. 2006;61:1157-65.

11. Sun Q, Townsend MK, Okereke OI, Franco OH, Hu FB, Grodstein F. Physical activity at midlife in relation to successful survival in women at age 70 years or older. Arch Intern Med. 2010;170:194-201. 
12. Lawton MP. Environment and other determinants of well-being in older people. Gerontologist. 1983;23:349-57.

13. Satariano WA. The epidemiology of aging: An ecological approach. Sudbury (MA): Jones and Bartlett Publishers, Inc.; 2006.

14. Perkins CC, Pivarnik JM, Paneth N, Stein AD. Physical activity and fetal growth during pregnancy. Obstet Gynecol. 2007;109:81-7.

15. Sundquist K, Qvist J, Sundquist J, Johansson SE. Frequent and occasional physical activity in the elderly: a 12-year follow-up study of mortality. Am J Prev Med. 2004;27:22-7.

16. Manini TM, Everhart JE, Patel KV, Schoeller DA, Colbert LH, Visser M, Tylavsky F, Bauer DC, Goodpaster BH, Harris TB. Daily activity energy expenditure and mortality among older adults. JAMA. 2006;296:171-9.

17. Sternfeld B, Wang H, Quesenberry CP, Jr., Abrams B, Everson-Rose SA, Greendale GA, Matthews KA, Torrens JI, Sowers M. Physical activity and changes in weight and waist circumference in midlife women: findings from the Study of Women's Health Across the Nation. Am J Epidemiol. 2004;160:912-22.

18. Nagi SZ. Some conceptual issues in disability and rehabilitation. In: Sussman $\mathrm{MB}$, editor. Sociology and rehabilitation. Washington (DC): American Sociological Association; 1965. p. 100-13.

19. Oxford Health Alliance. Oxford Vision 2020: Community interventions for health. Oxford, UK: Oxford Health Alliance; 2009.

20. Schnohr P, Scharling H, Jensen JS. Changes in leisure-time physical activity and risk of death: an observational study of 7,000 men and women. Am J Epidemiol. 2003;158:639-44.

21. Centers for Disease Control and Prevention. Trends in leisure-time physical inactivity by age, sex, and race/ethnicity--United States, 1994-2004. MMWR Morb Mortal Wkly Rep. 2005;54:991-4.

22. Kalache A, Kickbusch I. A global strategy for healthy ageing. World Health. 1997;50:4-5.

23. WHO. Global strategy on diet, physical activity and health: A framework to monitor and evaluate implementation. Geneva: WHO; 2006.

24. International Journal of Public Health. Physical activity in Europe. Int J Public Health. 2004;49:229-317.

25. Hakim AA, Petrovitch H, Burchfiel CM, Ross GW, Rodriguez BL, White LR, Yano K, Curb JD, Abbott RD. Effects of walking on mortality among nonsmoking retired men. N Engl J Med. 1998;338:94-9.

26. King AC. Interventions to promote physical activity in older adults. J Gerontol A Biol Sci Med Sci. 2001;56A:36-46.

27. Bravata DM, Smith-Spangler C, Sundaram V, Gienger AL, Lin N, Lewis R, Stave CD, Olkin I, Sirard JR. Using pedometers to increase physical activity and improve health: a systematic review. JAMA. 2007;298:2296-304.

28. U.S. Department of Health and Human Services. Physical activity and health: a report of the Surgeon General. Atlanta (GA): U.S. Department of Health and Human Services, Centers for Disease Control and Prevention, National Center for Chronic Disease Prevention and Health Promotion; 1996. 
29. Harrison RA, McElduff P, Edwards R. Planning to win: Health and lifestyles associated with physical activity amongst 15,423 adults. Public Health. 2006;120:206-12.

30. Burton LC, Shapiro S, German PS. Determinants of physical activity initiation and maintenance among community-dwelling older persons. Prev Med. 1999;29:422-30.

31. Cousins SO. Elderly tomboys? Sources of self-efficacy for physical activity in later life. J Aging Phys Act. 1997;5:229-43.

32. King AC, Stokols D, Talen E, Brassington GS, Killingsworth R. Theoretical approaches to the promotion of physical activity: Forging a transdisciplinary paradigm. Am J Prev Med. 2002;23:15-25.

33. Prohaska T, Belansky E, Belza B, Buchner D, Marshall V, McTigue K, Satariano W, Wilcox S. Physical activity, public health, and aging: critical issues and research priorities. J Gerontol B Psychol Sci Soc Sci. 2006;61:S267-73.

34. Nomaguchi KM, Bianchi SM. Exercise time: Gender differences in the effects of marriage, parenthood, and employment. J Marriage \& Family. 2004;66:413-30.

35. Cahill S, South K, Spade J. Outing age: public policy issues affecting gay, lesbian, bisexual and transgender elders. New York (NY): The Policy Institute of the National Gay and Lesbian Task Force Foundation; 2000.

36. Chao D, Foy CG, Farmer D. Exercise adherence among older adults: challenges and strategies. Control Clin Trials. 2000;21:212S-7S.

37. Ashworth NL, Chad KE, Harrison EL, Reeder BA, Marshall SC. Home versus center based physical activity programs in older adults. Cochrane Database Syst Rev. 2005(1):CD004017.

38. Rejeski WJ, Brawley LR, Ambrosius WT, Brubaker PH, Focht BC, Foy CG, Fox LD. Older adults with chronic disease: benefits of group-mediated counseling in the promotion of physically active lifestyles. Health Psychol. 2003;22:414-23.

39. Wood L, Giles-Corti B, Bulsara M. The pet connection: pets as a conduit for social capital? Soc Sci Med. 2005;61:1159-73.

40. King AC, Castro C, Wilcox S, Eyler AA, Sallis JF, Brownson RC. Personal and environmental factors associated with physical inactivity among different racial-ethnic groups of U.S. middle-aged and older-aged women. Health Psychol. 2000;19:354-64.

41. van Gool CH, Penninx BW, Kempen GI, Miller GD, van Eijk JT, Pahor M, Messier SP. Determinants of high and low attendance to diet and exercise interventions among overweight and obese older adults. Results from the arthritis, diet, and activity promotion trial. Contemp Clin Trials. 2006;27:227-37.

42. Wilcox S, King AC, Brassington G, Ahn D. Physical activity preferences of middle-aged and older adults: A community analysis. J Aging Phys Act. 1999;7:386-99.

43. King AC, Haskell WL, Young DR, Oka RK, Stefanick ML. Long-term effects of varying intensities and formats of physical activity on participation rates, fitness, and lipoproteins in men and women aged 50 to 65 years. Circulation. 1995;91:2596-604.

44. Seeman TE, Crimmins E. Social environment effects on health and aging: integrating epidemiologic and demographic approaches and perspectives. Ann N Y Acad Sci. 2001;954:88-117. 
45. Fried LP, Carlson MC, Freedman M, Frick KD, Glass TA, Hill J, McGill S, Rebok GW, Seeman T, Tielsch J, Wasik BA, Zeger S. A social model for health promotion for an aging population: initial evidence on the Experience Corps model. J Urban Health. 2004;81:64-78.

46. Vrazel J, Saunders RP, Wilcox S. An overview and proposed framework of social-environmental influences on the physical-activity behavior of women. Am J Health Promot. 2008;23:2-12.

47. Eyler AA, Matson-Koffman D, Vest JR, Evenson KR, Sanderson B, Thompson JL, Wilbur J, Wilcox S, Young DR. Environmental, policy, and cultural factors related to physical activity in a diverse sample of women: The Women's Cardiovascular Health Network Project. Women Health. 2002;36:1-134.

48. Belza B, Walwick J, Shiu-Thornton S, Schwartz S, Taylor M, LoGerfo J. Older adult perspectives on physical activity and exercise: voices from multiple cultures. Prev Chronic Dis. 2004;1:A09.

49. Marshall AL, Owen N, Bauman AE. Mediated approaches for influencing physical activity: update of the evidence on mass media, print, telephone and website delivery of interventions. J Sci Med Sport. 2004;7:74-80.

50. Merrill RM, Shields EC, White GL, Jr., Druce D. Climate conditions and physical activity in the United States. Am J Health Behav. 2005;29:371-81.

51. Saelens BE, Handy SL. Built environment correlates of walking: a review. Med Sci Sports Exerc. 2008;40:S550-66.

52. Frank LD, Engelke PO, Schmid TL. Health and community design: The impact of the built environment on physical activity. Washington (DC): Island; 2003.

53. Librett JJ, Yore MM, Schmid TL. Local ordinances that promote physical activity: a survey of municipal policies. Am J Public Health. 2003;93:1399-403.

54. Handy SL, Cao X, Mokhtarian PL. Does self-selection explain the relationship between built environment and walking behavior? Empirical evidence from Northern California. J Am Planning Assoc. 2006;72:55-74.

55. van Lenthe FJ, Martikainen P, Mackenbach JP. Neighbourhood inequalities in health and health-related behaviour: results of selective migration? Health Place. 2007;13:123-37.

56. Giles-Corti B, King A. Creating active environments across the life course: Thinking outside "the square". Br J Sports Med. 2009;43:109-13.

57. Carver A, Timperio AF, Crawford DA. Neighborhood road environments and physical activity among youth: the CLAN study. J Urban Health. 2008;85:532-44.

58. King AC, Toobert D, Ahn D, Resnicow K, Coday M, Riebe D, Garber CE, Hurtz S, Morton J, Sallis JF. Perceived environments as physical activity correlates and moderators of interventions in five studies. Am J Health Promot. 2006;21:24-35.

59. Waters J. Broke boomers may be forced to delay retirement. MarketWatch. 2008 May 19, 2008.

60. AARP. The economic turndown's impact on middle-aged and older Americans. 2008 May, 2008.

61. Litwin H, Sapir EV. Forgone health care due to cost among older adults in European countries and in Israel. Eur J Ageing. 2009;6:167-76. 
62. Ball K, Timperio A, Salmon J, Giles-Corti B, Roberts R, Crawford D. Personal, social and environmental determinants of educational inequalities in walking: a multilevel study. J Epidemiol Community Health. 2007;61:108-14.

63. Dunstan DW, Salmon J, Owen N, Armstrong T, Zimmet PZ, Welborn TA, Cameron AJ, Dwyer T, Jolley D, Shaw JE. Physical activity and television viewing in relation to risk of undiagnosed abnormal glucose metabolism in adults. Diabetes Care. 2004;27:2603-9.

64. Hu FB, Li TY, Colditz GA, Willett WC, Manson JE. Television watching and other sedentary behaviors in relation to risk of obesity and type 2 diabetes mellitus in women. JAMA. 2003;289:1785-91.

65. King AC, Goldberg JH, Salmon J, Owen N, Dunstan D, Weber D, et al. Identifying subgroups of U.S. adults at risk for prolonged television viewing to inform program development. Am J Prev Med. 2010;38:17-26.

66. Lee RE, King AC. Discretionary time among older adults: How do physical activity promotion interventions affect sedentary and active behaviors? Ann Behav Med. 2003;25:112-9.

67. Otten JJ, Jones KE, Littenberg B, Harvey-Berino J. Effects of television viewing reduction on energy intake and expenditure in overweight and obese adults: a randomized controlled trial. Arch Intern Med. 2009;169:2109-15.

68. Satariano WA, McAuley E. Promoting physical activity among older adults: from ecology to the individual. Am J Prev Med. 2003;25:184-92.

69. Hooker SP, Shoemaker W, Seavey W, Weidmer C. California Active Aging Project: Putting science into practice to promote physical activity for older adults. Gerontologist. 2000;40:260.

70. Wilcox S, Dowda M, Leviton LC, Bartlett-Prescott J, Bazzarre T, CampbellVoytal K, Carpenter RA, Castro CM, Dowdy D, Dunn AL, Griffin SF, Guerra M, King AC, Ory MG, Rheaume C, Tobnick J, Wegley S. Active for life: final results from the translation of two physical activity programs. Am J Prev Med. 2008;35:340-51.

71. Norman GJ, Zabinski MF, Adams MA, Rosenberg DE, Yaroch AL, Atienza AA. A review of eHealth interventions for physical activity and dietary behavior change. Am J Prev Med. 2007;33:336-45.

72. King AC, Friedman R, Marcus B, Castro C, Napolitano M, Ahn D, Baker L. Ongoing physical activity advice by humans versus computers: The Community Health Advice by Telephone (CHAT) Trial. Health Psychol. 2007;26:718-27.

73. InsideFacebook.com. Latest data on U.S. facebook age and gender demographics. 2008; Available from: http://www.insidefacebook. com/2008/09/18/latest-data-on-us-facebook-age-and-gender-demographics.

74. Weiner M, Callahan CM, Tierney WM, Overhage JM, Mamlin B, Dexter PR, McDonald CJ. Using information technology to improve the health care of older adults. Ann Intern Med. 2003;139:430-6.

75. Kremers SP, Visscher TL, Brug J, Chin A Paw MJ, Schouten EG, Schuit AJ, Seidell JC, Van Baak MA, Van Mechelen W, Kemper HC, Kok FJ, Saris WH, Kromhout D. Netherlands research programme weight gain prevention (NHFNRG): rationale, objectives and strategies. Eur J Clin Nutr. 2005;59:498-507. 
76. World Bank Global ICT Department. Financing information and communication infrastructure needs in the developing world: Public and private roles. 2005.

77. Sallis JF, Bowles HR, Bauman A, Ainsworth BE, Bull FC, Craig CL, Sjöström M, De Bourdeaudhuij I, Lefevre J, Matsudo V, Matsudo S, Macfarlane DJ, Gomez LF, Inoue S, Murase N, Volbekiene V, McLean G, Carr H, Heggebo LK, Tomten H, Bergman P. Neighborhood environments and physical activity among adults in 11 countries. Am J Prev Med. 2009;36:484-90.

78. Blair T, Minkler M. Participatory action research with older adults: key principles in practice. Gerontologist. 2009;49:651-62.

79. Minkler M, Wallerstein N, editors. Community based participatory research for health: Process to outcomes, 2nd edition. San Francisco (CA): Jossey Bass; 2008.

80. Snowdon W, Schultz J, Swinburn B. Problem and solution trees: a practical approach for identifying potential interventions to improve population nutrition. Health Promot Int. 2008;23:345-53.

81. Bornstein D, Pate RR, Pratt M. A review of the national physical activity plans of six countries. J Phys Act Health. 2009;6:S245-S64.

82. Pate RRE. A National Physical Activity Plan for the United States--Special Issue. J Phys Act Health. 2009;6:S157-S264.

83. Harrison RA, Roberts C, Elton PJ. Does primary care referral to an exercise programme increase physical activity one year later? A randomized controlled trial. J Public Health. 2005;27:25-32.

84. Kanis JA, Johnell O, Oden A, Johansson H, McCloskey E. FRAX and the assessment of fracture probability in men and women from the UK. Osteoporos Int. 2008;19:385-97.

85. Damush TM, Stewart AL, Mills KM, King AC, Ritter PL. Prevalence and correlates of physician recommendations to exercise among older adults. J Gerontol A Biol Sci Med Sci. 1999;54A:M423-M7. 